\title{
Racial Stereotypes and Gender in Context: African Americans at Predominantly Black and Predominantly White Colleges
}

\author{
Tabbye M. Chavous, ${ }^{1,3}$ Angel Harris, ${ }^{2}$ Deborah Rivas, ${ }^{1}$ \\ Lumas Helaire, ${ }^{1}$ and Laurette Green ${ }^{1}$
}

\begin{abstract}
In this study, relationships among stereotype expectations, gender, and academic self-concept and performance of African American students in predominantly White and predominantly Black college contexts were examined. Stereotype expectations are students' perceptions of biased treatment and evaluation within their major classroom settings (SE). Findings indicated that students' majors were related to stereotype expectations, as well as to their academic competence. Our results also provide evidence of gender and institutional interactions in the relationships between stereotype expectations and academic outcomes. Results are discussed in terms of the need to examine issues of race and gender in the academic experiences of African Americans, as well as how their specific school and classroom contexts may influence their experiences.
\end{abstract}

KEY WORDS: racial stereotypes; gender; African American college students.

This study constitutes an initial step in exploring the complex ways in which race and gender interact in the lives of African American students. Gender and race may function interactively in protective or enhancing ways as well as in ways that relate to difficulty in achieving academic success. Gender differences in the ways students perceive, experience, and respond to race-related academic experiences may help to explain differences in educational achievement and attainment outcomes for African American men and women in general and with regard to their outcomes in specific institutional settings.

It has been suggested that the racial makeup of a college environment influences African American students' academic experiences and outcomes (Allen, 1987, 1988, 1992; Davis, 1995;

\footnotetext{
${ }^{1}$ Department of Psychology, University of Michigan, Ann Arbor, Michigan.

${ }^{2}$ Department of Sociology, University of Michigan, Ann Arbor, Michigan.

${ }^{3}$ To whom correspondence should be addressed at Department of Psychology, University of Michigan, 525 E. University, Ann Arbor,
} Michigan 48109-1109; e-mail: tchavous@umich.edu.
Fleming, 1984; Nettles, 1988). However, there has been an ongoing debate as to what type of school environment is optimal for African American students. It has been argued that environments that require African Americans to interact with European American students will result in more positive educational experiences (e.g., Fordham, 1988) and that predominantly White college institutions (PWIs) provide superior academic resources (Wenglinsky, 1995). On the other hand, others have argued that only a race homogeneous institution can fulfill the social and academic needs of African American students (Baldwin, Duncan, \& Bell, 1987; Coleman, 1990).

Most empirical studies of African American college students have focused on students from one type of college environment-PWIs. Researchers consistently have cited the importance of a positive racial climate in the social and academic adjustment of African American students at PWIs (e.g., Cabrera, Nora, Terenzini, Pascarella, \& Hagedorn, 1999; Hurtado \& Carter, 1997; Nora \& Cabrera, 1996). Relatively few researchers have examined issues of 
race in the experiences of students on predominantly Black campuses. Some researchers assert that African American students fare better socially and academically at historically Black institutions (HBIs), because they emphasize philosophies more similar to those of the African American community than are found in mainstream institutions (Baldwin et al., 1987; Coleman \& Hoffer, 1987). This notion is supported by differences found in academic outcomes across students from HBIs and PWIs; HBI students show equal or higher levels of cognitive gains, persistence, and postgraduate educational attainment (Allen, 1992; Flowers \& Pasceralla, 1999a; Nettles, 1988; Wenglinsky, 1995). It is unclear, however, how African American students experience HBI settings, in particular the extent to which race and race-related experiences play a role in their college integration. Thus, the ways that the racial composition of HBIs functions to result in these attainment differences is unclear.

In addition to racial group membership, individuals' gender has implications for educational development and functioning. Some research has focused on gender differences in college attainment among African Americans; results show women attain higher education at higher rates than do men, and the researchers attributed these differences to social and educational barriers that affect men and women differentially (e.g., Cohen \& Nee, 2000). Even among African Americans who enter college, similar gender differences exist in both achievement and attrition (Fleming, 1984; Hare \& Hare, 1991; McJamerson, 1991). Little current research, however, has focused on how both gender and race relate to the college experiences of African Americans.

In this study, we focused on African American students from a PWI and an HBI. We examined students' perceptions of how race functioned for them in their college environment by assessing their racial stereotype expectations within academic class settings. We expected that stereotype expectations would be related to students' sense of belonging as well as to their academic self-concept and performance. Furthermore, we expected that students' stereotype perceptions would differ across gender and institutional context. In the following sections, we describe research related to African American students' college adjustment and incorporate research that points to the influences of gender and context within this population, and we discuss the importance of future inquiry about or concerning issues of race and gender in the educational experiences of African Americans.

\section{Racial Stereotypes and Academic Achievement}

Conceptual and research models of African Americans' achievement are based largely on the premise that African Americans are a stigmatized and devalued group in American society and, specifically, that this social status is a primary influence on their academic beliefs systems and behaviors (Chavous, Bernat, Schmeelke-Cone, Caldwell, Kohn-Wood, \& Zimmerman, 2003). Psychological researchers have posited that individuals who identify with a group that is not valued by the larger society may protect their self-concept by disengaging from domains in which their group members are expected to fare poorly (Crocker \& Major, 1989; Osbourne, 1997; Steele, 1992; Steele \& Aronson, 1995). African Americans' lower academic performance and persistence, then, is viewed, at least in part, as a function of the deleterious effects of negative cultural views of African Americans, or group stereotypes, on academic self-concept. Steele described this process as "stereotype threat," which occurs when individuals perceive that negative stereotypes about their group are salient in a particular situation or context. Here, the "threat" is represented by individuals' expectations that they may be viewed in ways that are consistent with these stereotypes (Steele, 1997). Subsequently, these expectations may result in pressures that negatively influence individuals' academic self-perceptions as well as their academic performance. Research has supported this perspective, as studies indicate that lower performance was found on academic diagnostic tasks for African American college students for whom race was made salient in experimental settings (e.g., Steele \& Aronson, 1995). Other researchers have concluded that perceiving negative views of African Americans is related to young peoples' development of beliefs in limited educational and social opportunities. Subsequently, researchers asserted that African American students may develop oppositional educational identities (Fordham \& Ogbu, 1986) and show lowered efficacy and effort in academic domains (Mickelson, 1990).

\section{Gender, Race, and Stereotypes}

Researchers have demonstrated that race plays an important role in the college experiences of African American students at PWIs. Furthermore, a great deal of research has been dedicated to the examination of the impact of gender on psychological and educational development (e.g., Belenky, Clinchy, 
Goldberger, \& Tarule, 1986; Beyer, 1999; Eccles, 1994; Sandler, Silverberg, \& Hall, 1996). There is a dearth of research, however, on issues of gender and education for African American populations. This omission is problematic in that frameworks for the examination of gender in education that have been developed and tested in predominantly European American student populations may not describe African American students accurately. For instance, research conducted with European American young people has shown that boys are viewed as having more social power than girls, are responded to more positively in classroom contexts, and have higher self-concept across social and academic domains (Belenky et al., 1986). A related area of research involves gender stereotypes and their relationship to classroom and school treatment, which suggests that men and boys are more likely to be viewed as intellectual compared to women and girls (Beyer, 1999). When we consider the research on African American college students, however, these "facts" may be less clear-cut.

First, as the rates of African American girls' and women's educational achievement and occupational attainment continue to increase, whereas those of African American boys' and men's decrease (Cohen \& Nee, 2000; Cross \& Slater, 2000), African American women might be viewed as having social power that exceeds that of African American men. Therefore, what is considered traditional gender status and behavior may not be typical for a number of African Americans. Furthermore, from an institutional perspective, Fleming (1984), in her earlier study of African American college students, and more recently, Allen (1992), Davis (1995), and Cokley (2000, 2001), suggested that PWI educational systems respond more negatively to African American men compared to African American women, and, as a result, women have higher academic self-concept (Allen, 1992). Fleming (1984) noted that women at PWIs did report experiencing racial discrimination and inequity but that, in contrast to men, they showed better adjustment, developing independence and assertiveness in response to aversive racial conditions. She suggested that the PWI environments allow for African American women's expressions of assertiveness more than they do for African American men's. In fact, she concluded that PWI environments encourage conformity among African American men more than among African American women, and, therefore, successful men also are less likely to be assertive in response to negative race related experiences. More recently, Chavous and colleagues compared African
American men and women at a PWI (Chavous, Rivas, Green, Helaire, \& Turner, 2002) and found that women felt less belonging on campus due to their ethnicity than men, but this perception of ethnic fit was more strongly predictive of academic adjustment outcomes for men. Perceiving the college environment as nonthreatening to one's cultural background, therefore, may be particularly important in African American men's adjustment at PWIs. Allen's (1992) and Davis's (1995) studies also suggest that unwelcoming PWI environments can be particularly detrimental for African American men and can result in men's experience of higher levels of anxiety about their academic competence and, ultimately, less intellectual growth.

In addition, the research on the impact of gender stereotypes in educational settings may not be fully applicable to African American students, as most of such research does not account for the possible interactions of gender and racial stereotypes. Conflicting perspectives exist on how these gender and race interactions may occur for African Americans. Some subscribe to the idea of the "double threat" where being a member of more than one oppressed social group results in cumulative risk outcomes (e.g., Brown, 2000). From the perspective of social identity frameworks, being a member of a group about whom there are negative stereotypes should be related to lower academic efficacy and academic disengagement (e.g., Crocker \& Major, 1989; Steele, 1992). It might be expected, then, that because African American women represent two social minority groups that are associated with negative academic stereotypes, they are most vulnerable for negative academic outcomes (Brown, 2000). The aforementioned research showing African American women's positive academic outcomes relative to African American men does not support this reasoning.

One possible explanation is that although Steele's paradigm of the deleterious effects of group stereotypes is thought to be applicable in the domains of race and gender independently (Steele, 1998), little work has been done on how racial stereotypes may function across gender. It is possible that the stereotypes about aggression and lack of academic aptitude that are associated specifically with African American men may influence differential responses to men and women. That is, stereotypes regarding gender and academic ability that have favored European American men and boys in educational settings may be replaced by "racialized" gender stereotypes. This can readily be seen in the college domain, for example, in 
discussions of African American men in the context of reform of academic standards for college athletes, discussions that often focus on sports in which African American men are highly represented or overrepresented relative to their numbers on PWI campuses. In these debates, it often is asserted that these student-athletes value academics either less than other students or not at all (Hare \& Hare, 1991); this results in a portrayal of African American men that is based primarily in their physical abilities and that is incongruent with academic success (Hall, 2001).

Furthermore, differential responses to African American men may be exacerbated by their higher visibility at PWIs, as African American men continue to be underrepresented relative to African American women in higher education (Cohen \& Nee, 2000) and overrepresented (relative to their numbers on campus) in sports such as basketball and football (Lederman, 1992). In her work on the effects of tokenism for women in organizational settings, Kanter (1977) suggested that members of a group that is severely numerically underrepresented in a given context are positioned in that context as representatives of their entire group, and, thus, are subject to others' expectations and generalizations of that group. Some negative consequences for "token" individuals include heightened performance pressures, exclusion from social interactions with members of the dominant group, and stereotyping along lines that places them in inferior positions. Thus, although African Americans as a whole are underrepresented in higher education, African American men actually may be more vulnerable to the effects of tokenism at PWIs. Little current research, however, has focused on gender differences in race-related experiences and perceptions on campus, nor on their impact for African American college students.

\section{Institutional Racial Composition as Context}

Although gender may relate to different academic experiences for African American students, the results of the aforementioned research also suggest the importance of considering specific college contexts in understanding students' educational experiences and development. Researchers who have compared African American students at PWIs and HBIs have noted differences in academic self-concept, grade point average, and postgraduate attainment (Allen, 1992; Cokley, 2000; Fleming, 1984; Sellers, Chavous, \& Cooke, 1998); HBI students showed higher performance and attainment outcomes. Al- though differences in outcomes suggest that students at HBIs have a different educational experience than do those at PWIs, little research has focused on racerelated student experiences at HBIs that may lead to these outcomes. In fact, researchers who have examined race experiences for African American college students have almost exclusively focused on PWIs. In this research, PWIs are presented as environments that are potentially threatening to the development of African American students through the impact of social isolation and institutional and person discrimination. Indeed, there is considerable evidence to support the idea that race-related experiences through classroom interactions, peer and faculty interactions, as well as perceived institutional climate greatly influence PWI minority students' college development (e.g., Allen, 1992; Cabrera et al., 1999; Hurtado, 1992).

HBIs, in contrast, often are represented as environments that are the opposite of the PWI experience as a function of their racial composition. Given that not all African American students at PWIs have poor adjustment, and, similarly, not every student at HBIs excels academically or adjusts seamlessly, it is important to understand how different students experience both types of settings to inform psychological and educational models of student development. In studies of college institutional effects, Pascarella and colleagues found that in HBI environments African American students not only were higher in objective measures of cognitive gains, but also reported higher perceived cognitive gains and increases in disciplinary understanding than did their counterparts at PWIs (Flowers \& Pascarella, 1999a; Pascarella, Smart, \& Stoecker, 1989). With regard to why these institutional differences might exist, Flowers and Pascarella (1999b) also found that HBI students were more likely to pursue learning activities for reasons of self-development and enhancement rather than for instrumental reasons (e.g., grades, course credit, resume enhancement/ getting a job) than were African American PWI students. These learning pursuits and outcomes may be related to why African American students feel a stronger sense of belonging at HBIs than those at PWIs (Allen, 1992). It is unclear, however, how or whether race functions in HBIs to result in such differences beyond the idea that there is "comfort in numbers."

In fact, in much of the discussion and study of HBI impact, one primary position about HBI environments has been suggested, either explicitly or implicitly. An assumption is made that discrimination 
does not exist in a predominantly African American setting, that the racial homogeneity of the setting protects students from racist experiences. Thus, the negative impact of racial stereotypes is viewed as less relevant or applicable in this type of environment. This assumption may not be fully tenable, as HBIs are not isolated from the racial dynamics of American society. HBIs have shown increasing numbers of European American instructors and non-American Black instructors, as well as nonAfrican American student peers (Foster, 2001). For instance, African American faculty represented only $59 \%$ of all faculty in HBI institutions in 1995, European American faculty represented $25 \%$, and Asian or Asian Americans made up about $8 \%$ of all HBI faculty members (News and Views, 1998; U.S. Department of Education, 1996). On some campuses, particularly those situated in or near urban areas, the representation of European American faculty exceeds $40 \%{ }^{4}$ European American students are not represented in as high proportion at HBIs, but their numbers have increased substantially over the last two decades (Foster, 2001). Furthermore, intragroup conflicts related to race (e.g., skin color, racial ideologies, social class, and endorsement of group stereotypes) may exist that could result in withingroup discrimination (Coard, Breland, \& Raskin, 2001). Blalock's early work (Blalock, 1956, 1958) on racial neighborhood migration patterns suggests that experiences of negative race-related experiences or discrimination are not solely contingent on the racial composition of the setting. To our knowledge, however, no published studies have concerned the influence of group stereotypes or negative race-related experiences on student academic outcomes in HBIs.

Further, little research including HBI students has focused explicitly on how issues of race and gender influence student experiences. In her 1984 study, Fleming found that African American men fared

\footnotetext{
${ }^{4}$ Historically HBIs have always had a White presence in teaching and administration, but initially, White participation had an underlying missionary objective of providing educational opportunity for disenfranchised African Americans (e.g., newly freed slaves and freedmen, those denied opportunity and rights in Jim Crow society). Over the last few decades, European Americans' entry into HBIs has been more based on shrinking employment opportunities in PWIs as well as a policy mandating the increased desegregation of HBIs (Gose \& Hebel, 2001; Mills \& Buckley, 1992). Some have argued that this change has resulted in a context that is less representative of HBIs' mission of providing environments for African American students that are caring and protective from negative social/racial dynamics (Gose \& Hebel, 2001).
}

better socially and academically at HBIs than did African American women. Fleming concluded that the social environment of the HBI setting favors men in terms of both social (e.g., dating opportunities, peer and organizational support) and academic domains. As at PWIs, women at HBIs are disproportionately represented compared to men (Allen, 1992), yet, as noted previously, this gender imbalance functioned differently in group-homogenous and group-minority college settings. Cokley (2001), in a recent study of African American students at an HBI, found that strong racial group identification was associated with higher academic self-concept for women but not for men. His findings suggest that African American men and women may have different types of race-related experiences in this type of setting.

\section{Academic Majors as Context}

In trying to understand institutional level differences in African Americans' race-related perceptions and subsequent adjustment, one important area of consideration is the more specific academic contexts that may influence students' views of race and education. It is likely that individual students' views of their university results in large part from her or his experiences and interactions within a number of smaller, more proximal contexts that she or he experiences on a regular or daily basis.

One way in which African American students' academic experiences may differ across college contexts and gender is within classroom settings. The academic units (departments, schools) in which students major represent a primary context of academic experiences and socialization (McJamerson, 1992). Research has shown gender differences in major and occupational goals, with men more highly represented in business, physical sciences, and medical fields, and women more highly represented in the humanities and social sciences (American Association of University Women, 1992; Bae \& Smith, 1996; Lips, 1992; Stumpf \& Stanley, 1996). Although most such research has not included many African American students, research that has included representative numbers of African American students (e.g., Simpson, 2001) indicates patterns of major choice across gender similar to that of European American students. Although African American students at PWIs are more likely than European American students and Asian students to choose disciplines that explicitly focus on issues of race, ethnicity, or culture, 
women still are more represented among these disciplines than men (Yancey, 1994). Furthermore, although women at HBIs are more likely to enter science, math, and other related professional majors than are those at PWIs, men are still represented at higher numbers than women are within these areas.

Although patterns of major choice may be similar in some ways for African American men and women relative to their European American counterparts, gender and race may play a role in African American students' experiences within their major areas in ways that differ from those of European American students or other ethnic minority students (Kim \& Sedlacek, 1996), and these experiences may differ across PWI and HBI environments. Research certainly has indicated the existence of negative racial stereotypes for African Americans concerning academic ability (Steele, 1997; Steele \& Aronson, 1995) and gender stereotypes concerning particular subject areas (e.g., girls are said to be more able in reading and less able in math and science; Beyer, 1999). African American men are more likely than African American women to be found in major areas at PWIs such as physical sciences and engineering, but African American men make up extremely small numbers of students in these disciplines overall. Consequently, African American men still may have to contend with social and academic isolation and treatment due to stereotypes based on their racial group membership. In contrast, African American women are highly underrepresented in those fields and may be overrepresented in social science and humanities relative to their numbers in the general college population, which results in somewhat less hypervisibility. Furthermore, these disciplines are more likely to allow students to address issues of race and diversity (e.g., within programs and course curricula) than are the traditional male-dominated major disciplines. Thus, African American men and women may have very different racial experiences as a function of the types of classroom contexts which they are most likely to enter and in which they usually interact.

\section{Study Aims}

In this study, we explored the roles of gender and college contexts among African American students. Specifically, we examined the role of gender in the relationships among stereotype expectations and college integration and academic adjustment. Although gender differences have been asserted in academic attainment and persistence for African Americans in higher education, less research has focused on factors that underlie these differences. Thus, we explored: (1) whether African American men and women differed in their stereotype expectations within their academic major class settings; (2) whether gender differences in stereotype expectations related to students' academic major and institutional contexts (PWI or HBI); and (3) the extent to which gender and institution moderate the relationships between stereotype expectations and academic outcomes (sense of belonging, academic competence, academic performance).

In our study of stereotype expectations, we chose to examine students' perceptions of their expected treatment in courses within their major, as these classes represent academic contexts that are extremely relevant to students as well as contexts in which they are likely to spend substantial periods of academic time. Furthermore, although we can think about contextual differences more broadly in terms of the racial composition of the environment, in understanding how students describe and interpret their educational settings, we thought it necessary to explore the types of experiences students may have in specific contexts within each of these settings. In this study, we expected gender differences in students' majors. Furthermore, we expected that these majors would be related to stereotype expectations, such that students in more male-traditional, "technical" majors (e.g., physical sciences, engineering) would report more stereotype expectations than would students in traditionally-female, "non-technical" majors (e.g., humanities, social sciences). We also hypothesized contextual and gender differences in stereotype expectations, in that HBI students would report lower stereotype expectations than would PWI students. Within institutions, we expected that men at PWI would experience more stereotype expectations than would women at the PWI. In contrast, women at HBI would experience more racial stereotype expectations than would HBI men. Finally, we hypothesized an interaction among gender, school, and stereotype expectations such that stereotype expectations would be more strongly related to sense of belonging and academic outcomes for men at the PWI and for women at the HBI.

\section{METHOD}

\section{Participants}

Participants consisted of 143 undergraduate students from a large, midwestern, public PWI (50 men 
and 93 women) and 134 students from a large southern, public HBI (43 men and 91 women). Both institution samples included students who represented all class years. PWI participants averaged about a sophomore level class year, and the HBI sample had a mean class year indicating a little above sophomore class level. For both institutional samples, the average mother's education level reported by students indicated some college attendance, and the average reported family income for both samples was between $\$ 31,000$ and $\$ 40,000$.

\section{Procedures}

Data were collected through mail-out surveys during Fall 1998. The survey questionnaire included measures of students' college experiences as well as questions that assessed student family and high school background. African American students' names and contact information were obtained from Registrar's lists, and school directories were used to obtain names and campus contact information for African American students at both institutions. At the PWI, surveys were sent to all African American students (15 students, however, could not be contacted due to inaccurate mailing addresses). At the HBI, as it was not possible to send surveys to all African American students (over 6000 students), a systematic sample of 600 students was selected (selection of every seventh student from a list of all African American students attending the university). Surveys were mailed to each of these students (minus 39 students with missing or inaccurate contact information). For both institution samples, follow-up surveys were mailed to maximize response rate. The final samples obtained ( $N=147$ at the PWI and $N=134$ at the HBI) reflect response rates of 37 and $27 \%$, respectively.

\section{Measures}

\section{Student Background}

Survey items were used to create variables that represented students' socioeconomic and demographic background characteristics: family income, mother's education, high school grade point average, current class year, and academic major. Students' family income was represented by students' reported family income prior to their college entry (responses were on an 8-point scale that ranged from “\$0-\$10,000" to “ $\$ 71,000+")$. A parental education variable was created from students' indication of their mothers' education level (a 5-point scale that ranged from "less than high school" to "doctorate or professional"). Individual items assessed students' reported cumulative high school grade point average, their current college class year, as well as their major. (Note: Responses for freshmen in the sample primarily indicated students' officially declared majors. For freshmen students from the PWI sample, however, major also could reflect their intended majors).

\section{Stereotype Expectations in Major}

Three items were used to assess participants' perceptions and expectations of biased evaluative treatment within their academic major classes. Responses were made on a 5-point likert scale that ranged from "strongly disagree" to "strongly agree." All responses were coded such that higher scores indicate more expectations of racial stereotyping and biased evaluation. Items were taken from a stereotype threat measure by Steele and Aronson (1995) used in experimental settings. Items were modified to reflect students' perceptions specifically within their academic major classes. Example items are: "The professors in this type of class expect me to do poorly because of my race" and "My race does not affect people's perceptions of my ability in this type of class" (reverse coded). In the present sample, Cronbach's alphas indicate high to moderately high internal consistency ( $\alpha=.83$ at the PWI and $\alpha=.75$ at the HBI).

\section{Sense of Belonging in Major}

Participants completed the Sense of Belonging dimension of the Perceived Cohesion Scale (Bollen \& Hoyle, 1990). The scale was made up of three items for which respondents indicated on a 5-point scale the extent to which they felt themselves connected to and part of their major classroom settings. Example items include: "I feel a sense of belonging to my classmates" and "I see myself as part of the classroom setting." Bollen and Hoyle's (1990) tests of the measure indicate good scale reliability with college students. In the present study, the scale showed high internal consistency at both institutions ( $\alpha=.83$ at the PWI and $\alpha=.86$ at the HBI).

\section{Academic Competence in Major}

The academic subscale of the Perceived Competence Scale (Harter, 1982) was used to assess 
students' self-evaluations of their ability and skill within their major areas. The scale has been used in numerous studies with children, older adolescents, and young adults and has shown good reliability with youth from multiple ethnic backgrounds (e.g., Alva \& Reyes, 1999; Cairns, McWhirter, \& Duffy, 1990; Smith \& Brody, 2000). Items were based on a 5point likert scale that ranged from "strongly disagree" to "strongly agree." The scale items were modified for the present study to reflect college students' selfperceptions within their academic major classes, e.g., "I can figure out answers to assignments in this type of class" and "I am just as smart as others in this type of class." The scale yielded good internal consistency at both the PWI and HBI ( $\alpha$ 's $=.94$ and .88 , respectively).

\section{Academic Performance}

Respondents' academic performance was assessed through their self-reported cumulative grade point average (GPA).

\section{RESULTS}

Participants were compared across background variables (family income, mother's education, and high school GPA) across gender and institution using Analyses of Variance (ANOVAs). No institutional differences were found for family income or mother's education, but the institutions differed significantly for high school GPA (at the PWI, $M=3.30, S D=.47$, and at the HBI, $M=3.01, S D=.49)$. No gender differences or gender $\times$ institutional relationships were found across the background variables.

To address the idea that gender differences in academic experiences may relate to the types of academic settings that men and women select, we examined gender and institutional differences in the majors students selected. Students' reported academic majors were coded to represent four main categories: (1) Social Sciences, (2) Education, (3) Natural Sciences (which included Pre-Med), (4) Engineering/Computer Technology/or Business (this category represented majors that heavily relied on technological resources). All other responses were coded as (5) "Other." Chi-square analyses were used to examine the proportions of men and women represented in different major areas for each school. For the PWI sample, findings indicated significant differences in numbers of men and women across major types compared to what would be expected by chance, $\chi^{2}(4, N=143)=23.68, p<.001$. With the exception of natural sciences, men were represented in higher proportions in traditionally-male dominated ("technical") majors, whereas women predominated in traditionally female-dominated ("nontechnical") majors. No significant gender differences in students within particular majors were found for the HBI, $\chi^{2}(3, N=134)=6.29 p<.10$. Table I displays students' major choices across gender and college type.

Because of small numbers of individuals within particular major areas, for subsequent analyses, a dichotomous variable was created for major to indicate the traditionally male-dominated, "technical" majors and the traditionally female-dominated, "nontechnical" majors (chi-square analyses of this dichotomous variable yielded identical patterns for gender and school). To explore whether men and women have different racial experiences within their academic majors, we conducted Analysis of Covariance (ANCOVA), examining gender, institution, and major as predictors of stereotype expectations (SE), with class year, family income, and high school GPA included as control variables. A significant model resulted, $F(10,277)=3.81, p<.001$, and school differences were found in stereotype expectations; PWI students had higher score SE scores than did HBI students $(M=2.7, S D=.90$ and $M=2.2$, $S D=.82)$. A significant effect for major type also

Table I. Summary of Major Choices Across Gender and Institution

\begin{tabular}{lccccc}
\hline & $\begin{array}{c}\text { Social } \\
\text { sciences }\end{array}$ & Education & $\begin{array}{c}\text { Natural } \\
\text { sciences }\end{array}$ & $\begin{array}{c}\text { Engineering/Computer } \\
\text { science/Business }\end{array}$ & Other \\
\hline $\begin{array}{l}\text { PWI }(N=143) \\
\quad \text { \% of men in major }\end{array}$ & 20.4 & 8.2 & 0 & 65.3 & 6.1 \\
$\quad$ \% of women in major & 35.5 & 11.8 & 20.4 & 30.1 & 2.2 \\
$\begin{array}{l}\text { HBI }(N=134) \\
\quad \text { \% of men in major }\end{array}$ & 46.5 & 18.6 & 2.3 & 32.6 & 0 \\
\% of women in major & 56.0 & 15.4 & 11 & 17.6 & 0 \\
\hline
\end{tabular}


Table II. Means and Standard Deviations of Stereotype Expectations by Gender, Institution, and Major

\begin{tabular}{lll}
\hline & \multicolumn{2}{l}{ Stereotype expectations } \\
\cline { 2 - 3 } & \multicolumn{1}{c}{$M$} & $S D$ \\
\hline Gender & 2.39 & 0.76 \\
$\quad$ Men & 2.42 & 0.88 \\
$\quad$ Women & & \\
Institution & $2.70^{* * *}$ & 0.90 \\
$\quad$ PWI & 2.20 & 0.82 \\
$\quad$ HBI & & \\
Major & $2.60^{* * *}$ & 1.01 \\
$\quad$ Traditionally male-dominated & \\
$\quad$ "Technical” majors & & 0.78 \\
$\quad$ Traditionally female-dominated & 2.30 & \\
$\quad$ "Non-technical” majors & & \\
*** $p<.01$. & & \\
&
\end{tabular}

was found, and it showed a higher SE mean for traditionally male-dominated majors $(M=2.6$, $S D=1.01)$ than for traditionally female-dominated majors $(M=2.3, S D=.78)$. No significant effects were found for gender or for any interactions among gender, institution, and major. (See Table II for summary information for this analysis).

Next, we conducted hierarchical regression analyses to test predictive models for sense of belonging, academic competence and GPA (Aiken \& West, 1991). Table III summarizes the results of these analyses. For each model, student background (family income, mother's educa- tion, high school GPA), and class year were entered in a first step. Dichotomous variables that represent gender $($ men $=1$ and women $=2$ ), institution (PWI = 1 and HBI $=2$ ), and major (traditionally male-dominated, "technical" majors $=1$, traditionally female-dominated, "nontechnical" majors $=2$ ), as well as the centered stereotype expectations variable were included in Step 1. Variables representing multiplicative interactions (calculated based on Aiken \& West, 1991) among gender, institution, and stereotype expectations were included in Step 2 (i.e., gender $\times$ institution, gender $\times$ stereotype expectations, institution $\times$ stereotype expectations, and gender $\times$ institution $\times$ stereotype expectations).

First, we examined whether gender, institution, and stereotype expectations were predictive of students' sense of belonging in major. Results indicated a significant predictive model, $F(7,277)=14.30, p<$ .001 , Adjusted $R^{2}=.35$. Significant relationships with class year, $b=.14, p<.01$, institution, $b=.51, p<$ .001 , major, $b=-.32, p<.01$, and stereotype expectations, $b=-.39, p<.001$, were found in Step 1, but only class year and major remained significant when the interaction terms were added in Step 2. None of the interaction terms showed significant relationships with sense of belonging.

For the academic competence model $F(7,277)=$ $4.02, p<.001$, significant relationships with class year, $b=.10, p<.05$, and stereotype expectations, $b=-.21, p<.01$, were found when these variables

Table III. Hierarchical Regression of Sense of Belonging, Academic Competence, and Grade Point Average on Student Background, Stereotype Expectations (SE), and Gender, Institution, SE Interaction Variables

\begin{tabular}{|c|c|c|c|c|c|c|}
\hline & \multicolumn{6}{|c|}{$b$} \\
\hline & \multicolumn{2}{|c|}{ Sense of belonging } & \multicolumn{2}{|c|}{ Academic competence } & \multicolumn{2}{|c|}{ Grade point average } \\
\hline & Step 1 & Step 2 & Step 1 & Step 2 & Step 1 & Step 2 \\
\hline Class year & $.14^{* * *}$ & $.15^{* * *}$ & $.10^{* *}$ & $.11^{* * *}$ & .01 & $.01^{* *}$ \\
\hline Family income & -.01 & -.02 & .01 & .01 & -.01 & -.01 \\
\hline Mother's education & -.05 & -.05 & -.03 & -.03 & -.01 & -.01 \\
\hline High school GPA & .13 & .15 & .09 & .09 & $.33^{* * * *}$ & $.34^{* * * *}$ \\
\hline Major $(1=$ trad. men, $2=$ trad. women $)$ & $-.32^{* * *}$ & $-.32^{* * *}$ & -.15 & -.16 & .04 & .05 \\
\hline Gender $(1=$ men, $2=$ women $)$ & -.02 & $-.13^{+}$ & -.02 & $-.42^{* *}$ & .07 & .12 \\
\hline Institution (1 = PWI, 2 = HBI $)$ & $.51^{* * * *}$ & -.19 & -.02 & $-.57^{* * *}$ & $.24^{* * *}$ & .32 \\
\hline \multirow[t]{3}{*}{ Stereotype expectations (SE) } & $-.39^{* * * *}$ & -.37 & $-.21^{* * *}$ & .09 & $-.48^{* * *}$ & -.09 \\
\hline & \multicolumn{2}{|c|}{ Adj $R^{2}=.33$} & \multicolumn{2}{|c|}{ Adj $R^{2}=.07$} & \multicolumn{2}{|c|}{ Adj $R^{2}=.09$} \\
\hline & \multicolumn{2}{|c|}{$\Delta R^{2}=.33$} & \multicolumn{2}{|c|}{$\Delta R^{2}=.07$} & \multicolumn{2}{|c|}{$\Delta R^{2}=.09$} \\
\hline Gender $\times$ Institution & & $.43^{*}$ & & $.50^{* * *}$ & & -.05 \\
\hline Institution $\times \mathrm{SE}$ & & .07 & & $-.72^{* *}$ & & .19 \\
\hline Gender $\times$ SE & & -.19 & & -.44 & & $.39^{* *}$ \\
\hline \multirow[t]{3}{*}{ Gender $\times$ Institution $\times \mathrm{SE}$} & & .08 & & $.42^{* *}$ & & -.16 \\
\hline & & $\mathrm{j} R^{2}=.35$ & & $\mathrm{j} R^{2}=.11$ & & lj $R^{2}=.12$ \\
\hline & & $\Delta R^{2}=.02$ & & $\Delta R^{2}=.04$ & & $\Delta R^{2}=.03$ \\
\hline
\end{tabular}

${ }^{*} p<.06 .{ }^{* *} p<.05 .{ }^{* * *} p<.01 .^{* * * *} p<.001$. 


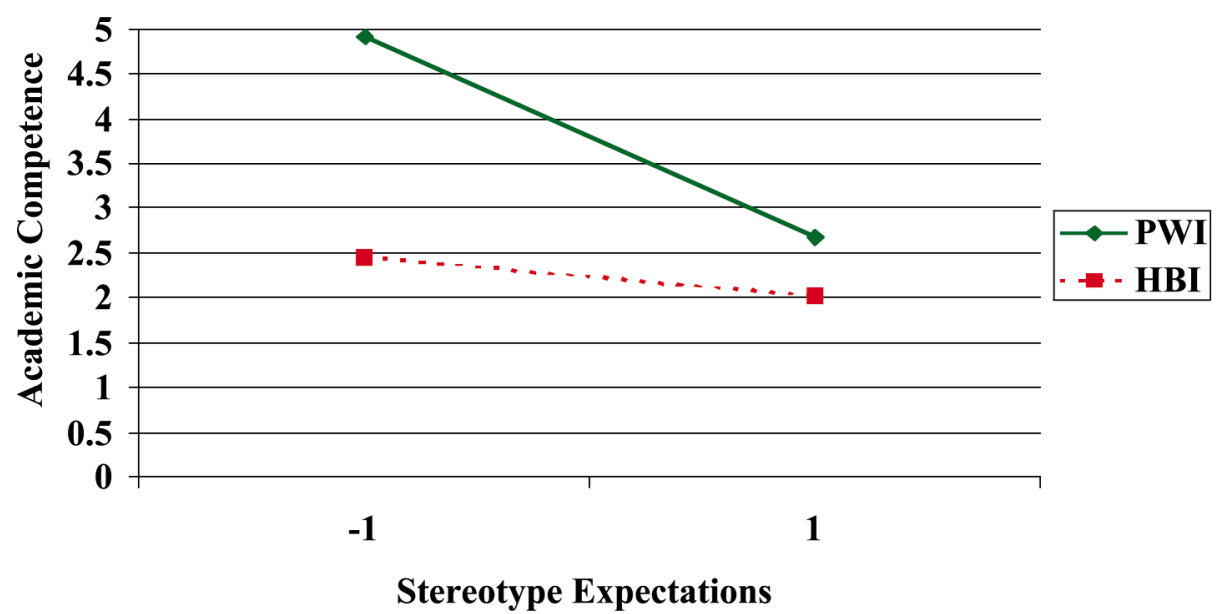

Fig. 1. Summary of interaction of SE and institution in predicting academic competence.

were entered in Step 1. The beta coefficients for class year remained significant when the interaction terms were entered in Step 2. In the final model, which accounted for $11 \%$ of variation in academic competence, significant coefficients also resulted for the gender $\times$ institution interaction, $b=.50, p<.01$, institution $\times \mathrm{SE}, b=-.72, p<.05$, and gender $\times$ institution $\times \mathrm{SE}, b=.42, p<.05$. Figures 1 and 2 display the institution $\times$ SE interaction and the three-way interaction of institution, gender, and SE on academic competence.

To examine the gender $\times$ institution interaction, we performed post hoc ANCOVAs, which indicated that women at the HBI $(M=4.33, S D=.53)$ had significantly higher academic competence than did women at the PWI $(M=4.11, S D=.84)$. In Fig. 1 , the effect for the interaction of institution $\times \mathrm{SE}$ on academic competence is plotted. In post hoc analyses, we tested separate regression models for each institution and conducted simple slope tests (Aiken \& West, 1991) to determine whether the simple slopes for the regression lines for the HBI and PWI differed significantly from zero as well as from each other. These analyses allowed us to determine whether the prediction of academic competence from SE differed significantly across institution. In each regression model, we included student background variables and major as control variables. Results from the regression models confirmed the regression of academic competence on SE for the PWI sample, $F(6,143)=3.41, p<.01$,

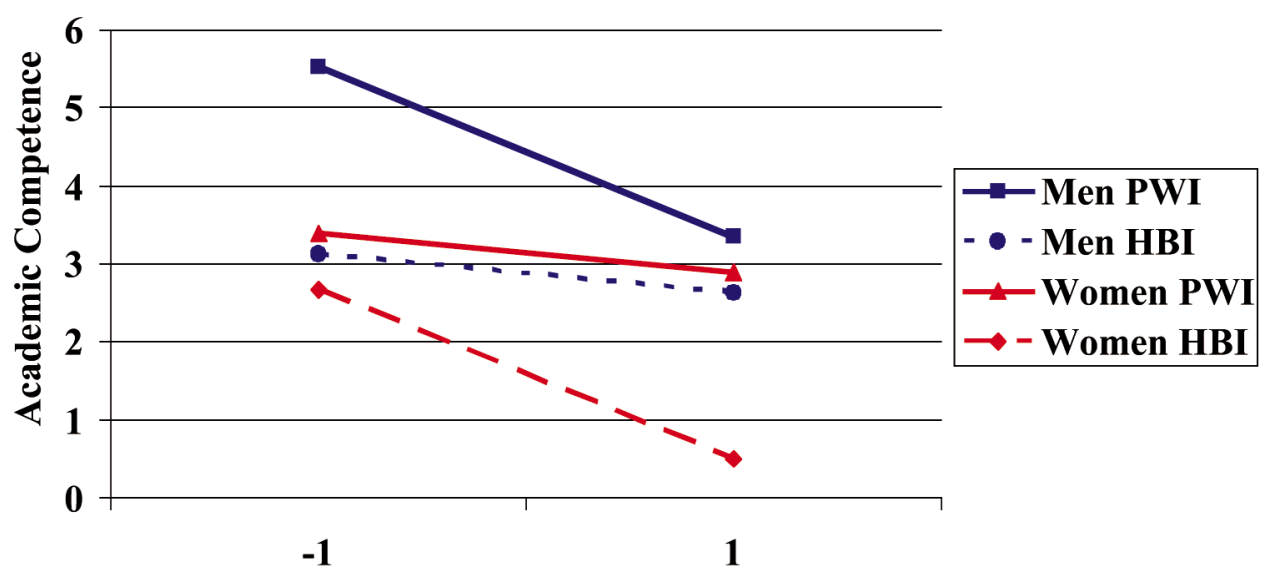

Stereotype Expectations

Fig. 2. Summary of three-way interaction (gender $\times$ institution $\times$ SE) predicting academic competence. 
and the HBI sample, $F(6,134)=3.28, p<.01$, which showed negative relationships between SE and academic competence, $b=-.15, p<.05$ and $b=-.17$, $p<.01$ respectively. Our $t$ tests of differences between slopes showed a significant difference between the simple slopes for the PWI and the HBI, which indicated that the regression of academic competence on $\mathrm{SE}$ varies across institution.

For the three-way interaction gender $\times$ institution $\times$ SE (see Fig. 2), post hoc regression analyses first were conducted for men and women attending the PWI, after controlling for student background and major. Results indicated a significant predictive model, $F(5,50)=2.11, p<.05$, for the regression of academic competence on stereotype expectations for PWI men only, $b=-.25, p<.05$. In contrast, regression analyses for women and men at the HBI showed a significant predictive model only for women, $F(5,91)=2.54, p<.05$, where SE was negatively related to academic competence, $b=-.13, p<.05$. Further, $t$ tests of slopes for gender within each institution demonstrated significant differences between the slopes for men and women at both institutions.

Finally, the predictive model for GPA was significant, $F(7,277)=4.44, p<.001$. Stereotype expectations showed a significant, negative relationship with GPA in Step 1, $b=-.48, p<.05$, but the SE coefficient became nonsignificant when the interaction terms were added in Step 2. In the overall model, a significant gender $\times$ SE interaction resulted, $b=.39, p<.05$. (See Fig. 3). Post hoc regression analyses indicated that SE was negatively related to GPA for men, Model $F(6,93)=2.10, b=-.15$, $p<.05$, but a significant relationship was not found for women. Post hoc $t$ tests of differences between slopes also confirmed that the prediction of GPA by SE differed significantly for men and women.

\section{DISCUSSION}

The persistent gender achievement gap among African American students within higher education warrants attention to the ways both race and gender may influence their experiences on college campuses. A primary objective of this study was to begin to explore how race, gender, and institutional context may interact to influence academic experiences, academic self-evaluations, and achievement among African American students in higher education. A strength of our study was the focus on both institution and academic major areas as contexts of investigation. Overall, our findings suggest that racial stereotypes may function in different ways for African American men and women, depending on their institutional and academic contexts.

\section{Gender and Institutional Differences in Stereotype Expectations}

As expected, HBI students perceived less racially stereotyped treatment in their classes than did PWI students. Our results also demonstrate, however, that race does play a salient role for students at both types of institutions, as students in both settings

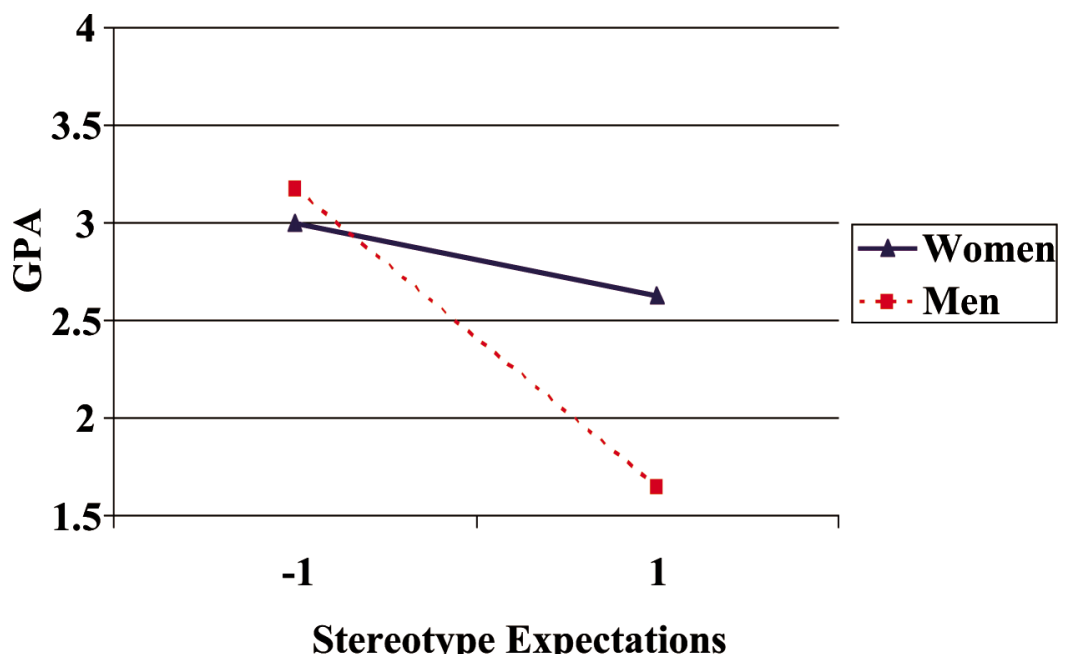

Fig. 3. Summary of Gender $\times$ SE interaction predicting grade point average. 
reported perceiving racially biased evaluation or treatment in major classes. Thus, although HBIs may foster stronger sense of belonging and connection than PWIs (found in this study as well as in past noted research, e.g., Allen, 1992), HBI students are not insulated from issues of race and discrimination (Phelps, Tranakos-Howe, Dagley, 2001; Sellers, Chavous, \& Cooke, 1998).

It is interesting that, within each institution and within academic majors, women and men did not differ in their stereotype expectations. The findings do not support the "double threat" (e.g., Brown, 2000) or the social identity perspectives (e.g., Crocker \& Major, 1989, Steele, 1997) from which we would reason that women would perceive more negative treatment in traditionally male-dominated fields. Instead, being in particular types of academic disciplines, regardless of gender, seemed to be related to racial stereotype perceptions. In this case, the more traditionally male-dominated fields may lend themselves more to ability stereotypes based on race (e.g., in math and science where African Americans are extremely underrepresented) than traditionally female-dominated disciplines. The differences in men's and women's race-related perceptions in this study seem to be related more to their representation in particular disciplines than to differential race perceptions within their academic settings.

\section{Stereotype Expectations and PWI Academic Adjustment}

Our findings indicate that having fewer expectations of racial stereotypes in major classes was related to higher academic competence self-perceptions for men at the PWI. The findings are consistent with past researchers' positions that African American men and women have different experiences at PWIs (Allen, 1992; Davis, 1995; Fleming, 1984) and that the academic self-concept of women at PWIs are less negatively affected by perceptions of discrimination (Fleming, 1984). The lack of significant relationships between stereotype expectations and competence for PWI women is particularly striking given that men and women at this institution did not differ in their expectations, nor in their precollege background characteristics.

Despite these findings, we would not conclude that issues of racial climate and discrimination in their college environments do not affect the college experiences of African American women at PWIs.
The findings do suggest, however, that gender differences exist in terms of how African American students experience and respond to their college campus. Given that African American men are less prevalent on PWI campuses than are African American women, they may be more vulnerable to the effects of having stereotype expectations, as there are fewer men like themselves to whom to look for social support when these expectations occur. Furthermore, gender differences in help seeking or social support behaviors (Fleming, 1984; Robertson, 2001) may play a role in the different relationships between SE and adjustment outcomes for PWI men and women.

Another possibility for further inquiry is that men and women at PWIs may experience different types of racial discrimination or race-related treatment on campus. Researchers on gender and education (e.g., Sandler et al., 1996) have characterized the experiences of women by feelings of invisibility, in that women are noticed and called upon less than men are. Although this research did not focus on African American students, it is plausible that for African American women in PWI settings, being both female and an ethnic minority group member may be related to more subtle forms of discrimination, such as being ignored in academic settings. This type of treatment may not be related to the academic competence and performance outcomes assessed in this study; however, women's negative race-related experiences may relate to other outcomes not assessed in our study, such as psychological well-being or even students' decisions to enter specific majors or fields of study.

Educational research with European American men suggests that men receive more attention from instructors. African American men, however, may receive negative attention relative to European American men, as they are hypervisible, and racial stereotypes concerning academic ability may influence how they are responded to in academic settings. Furthermore, it is possible that the types of discrimination that men experience have a stronger impact on self-concept and positive academic behaviors (e.g., engaging in study groups, seeking help from faculty), and, subsequently, on performance. Our finding that, across PWI and HBI settings, stereotype expectations were a stronger predictor of GPA for men than for women also shows the necessity of further exploring the different ways that gender relates to how African Americans experience college. 


\section{Stereotype Expectations and HBI Academic Adjustment}

SE was related more strongly to men's than women's academic outcomes at the PWI, whereas the opposite pattern was found at the HBI, where stereotype expectations related to lower academic competence for women than for men at the HBI. Bowman, Kite, Branscombe, and William (1999) contended that African American women at PWIs and HBIs experience their educational environments differently (Bowman, Cureton, Mellum, Alarcon, Altareb, \& Valtinson (1995). They suggested that because African Americans are numerical and social minorities at PWIs, they may experience the environment primarily in terms of race. In contrast, at HBIs race is less salient, thus, women may be more likely to experience and interpret their environment in terms of race as well as in ways that are more consistent with societal gender hierarchies (e.g., attributing discrimination or bias in a science major to being an African American woman). In their study of women from an HBI and a PWI, students were presented with vignettes in which an instructor made negative remarks to a female student regarding her performance. Women attending the HBI were more likely to attribute the remark to both racial and gender discrimination, whereas those at the PWI were more likely to attribute the remark to racial discrimination only.

Regarding the findings of this study, it is possible that some women at the HBI may be experiencing their classroom contexts in "gendered" ways. Although race hypervisibility may be a lesser concern at HBIs, women at these institutions may experience more hypervisiblity within traditionally male-dominated majors due to their gender, and traditional stereotypical beliefs about gender and math/science ability may influence their classroom treatment and evaluation more than at PWIs. Furthermore, African American women at HBIs may be more likely than those at PWIs to attribute discriminatory treatment or perceive being stereotyped by instructors as a function of being an African American woman rather than to being a woman or to being an African American. Subsequently, their competence self-perceptions in academic settings may be more negatively affected by experiences of discrimination than is the case for their male counterparts at HBIs.

Clearly, our findings suggest a number of possibilities worthy of future inquiry by psychological and educational researchers. Because we have information from only one period in time, we did not ask respondents exactly how they came to expect racially biased treatment in their class settings. Thus, we cannot determine how or whether African American men are experiencing different types of responses and reactions from their college institution than are African American women (e.g., teachers, peers, community members, local media portrayals), or whether the men are more likely to enter PWI environments with more apprehension about race and stereotypes. As gender has been linked with attributional style in relation to performance (Campbell \& Henry, 1999; Wiley \& Crittenden, 1992), another potential area of inquiry involves whether men and women engage in different strategies to deal with discrimination, for instance, whether men are more likely than women to respond to negative academic performance or experiences with attributions about race and discrimination and the effect of these strategies on performance and perceptions. Also, as we did not assess students' perceptions of gender stereotypes, future researchers also could explore how African American men and women integrate gender and race in the ways they experience their academic settings.

Finally, the results suggest the need to gain a better understanding of how race and gender functions for African Americans in race-homogenous environments. We assert that racial stereotypes are related to student experiences at both PWI and HBI institutions; however, they may occur and affect students in different ways. It is unclear, for instance, whether HBI students are perceiving stereotypes from European Americans, from members of other ethnic groups, or from other African Americans. (In the case of the HBI institution in this study, although African American professors predominated, it also had a number of European American faculty and non-African American faculty of Color.) Most stereotype threat research frameworks (e.g., Steele, 1997, and other research based on this paradigm) address African American students' academic experiences in majority White settings. This research suggests that perceiving racial stereotypes in group-predominant settings also may impact student academic development and in ways that vary across gender.

Overall, our findings suggest a need to examine both individual perceptions of institutions as well as institutional structures, instructional practices, policies, and other sources that may convey messages about belonging and fit to African American students. In interpreting our study's findings and generalizing to other students at other universities, it is important to note that the selective samples of African American 
students who chose to attend these particular institutions may not be representative of the broader African American population or even to all African American college students. Because of our response rates for the two institutions, we cannot conclude that students who chose to respond to the survey are similar in terms of their racial experiences to those who did not respond. Second, colleges differ in the types of students they select, as well as in the types of environments they provide. Finally, issues of design and methodology may influence what can be concluded from the study's findings. Class year was controlled for in study analyses, therefore, statements could be made regarding intergroup class year differences in study outcomes. The cross-sectional nature of the study, however, does not allow the examination of intraindividual change, or the extent to which students' expectations of stereotypes increase or decrease in response to their college environment as well as the influence of performance on beliefs and perceptions. Longitudinal research on multiple samples of students across their educational experience could help clarify these issues.

\section{Conclusions}

Despite the above limitations, our study findings have several important implications. Most important, the findings indicate the heterogeneity of African American students, that their academic adjustment processes may differ according to gender and institutional contexts. An implication of our findings is that the continued examination of multiple indicators of academic progress is necessary. Thinking about "successful integration" in terms of self-concept, sense of connectedness and belonging, and performance, as well as how students' experiences lead to these different outcomes, seems to be especially important, given that our findings indicate different relationships between classroom perceptions and each of these adjustment outcomes for men and women and across institutional contexts. Furthermore, research on college students has shown noncognitive indicators (such as self-concept and satisfaction) to be as important predictors of retention for African American students as are cognitive factors (Murguia, Padilla, \& Pavel, 1991). Clearly there is a need for researchers to engage in research that challenges and explicitly tests current psychological and educational theory and models for African American men and women. Doing so will allow us to develop culturally accurate theoretical frameworks that do not assume that all African Americans view and experience race and gender similarly to men and women in other ethnic or cultural groups. Nor should our frameworks assume that all African Americans fare similarly within specific academic settings.

\section{REFERENCES}

Aiken, L. S., \& West, S. G. (1991). Multiple regression: Testing and interpreting interactions. Newbury Park, CA: Sage.

Allen, W. (1988). The education of Black students on White college campuses: What quality the experience? In M. T. Nettles (Ed.), Toward Black undergraduate student equality in American higher education (pp. 57-86). New York: Greenwood.

Allen, W. R. (1987). Black colleges versus White colleges: The fork in the road for Black students. Change, 19(3), 28-34.

Allen, W. R. (1992). The color of success: African American college student outcomes at predominantly White and historically Black colleges and universities. Harvard Educational Review, $62,26-44$.

Alva, S. A., \& Reyes, R. (1999). Psychosocial stress, internalized symptoms, and the academic achievement of Hispanic adolescents. Journal of Adolescent Research, 14, 343-358.

American Association of University Women. (1992). How schools shortchange girls: A study of major findings of girls and education. Washington, DC: Author.

Bae, Y., \& Smith, T. M. (1996). Issues in focus: Women in mathematics and science. Washington, DC: National Center for Education Statistics.

Baldwin, J., Duncan, J. A., \& Bell, Y. R. (1987). Assessment of African self-consciousness among Black students from two college environments. Journal of Black Psychology, 13(2), 27-41.

Belenky, M. F., Clinchy, B. M., Goldberger, N. R., \& Tarule, J. M (1986). Women's ways of knowing. New York: Basic Books.

Beyer, S. (1999). The accuracy of gender stereotypes. Sex Roles, $40,787-813$.

Blalock, H. M. (1956). Economic discrimination and Negro increase. American Sociological Review, 21, 584-588.

Blalock, H. M. (1958). A note on adjusting discrimination rates for percent non-White. Journal of Negro Education, 27, 66-68.

Bollen, K. A., \& Hoyle, R. H. (1990). Perceived cohesion: A conceptual and empirical examination. Social Forces, 69, 479-504.

Bowman, S. L., Cureton, V., Mellum, K. M., Alarcon, M., Altareb, B., \& Valtinson, G. (1995, August). African American or female: How do we identify ourselves? Paper presented at the annual meeting of the American Educational Research Association, New York, NY.

Bowman, S. R., Kite, M. E., Branscombe, N. R., \& Williams, S. (1999). Developmental relationships of Black Americans in the academy. In A. Murrell (Ed.), Mentoring dilemmas: Developmental relationships within multicultural organizations (pp. 21-46). Mahwah, NJ: Erlbaum.

Brown, T. (2000). Gender differences in African American students' satisfaction with college. Journal of College Student Development, 41, 479-487.

Cabrera, A. F., Nora, A., Terenzini, P. T., Pascarella, E., \& Hagedorn, L. S. (1999). Campus racial climate and the adjustment of students to college: A comparison between White students and African American students. Journal of Higher Education, 70(2), 134-160.

Cairns, E., McWhirter, L., \& Duffy, U. (1990). The stability of self-concept in late adolescence: Gender and situational effects. Personality and Individual Differences, 11, 937-944.

Campbell, C. R., \& Henry, J. W. (1999). Gender differences in self-attributions: Relationship of gender to attributional 
consistency, style, and expectations for performance in a college course. Sex Roles, 41, 95-104.

Chavous, T. M., Rivas, D., Green, L., Helaire, L., \& Turner, W. (2002, April). Gender and race in the academic development of African American students. Paper presented at the Annual Meeting of the American Educational Association, New Orleans, LA.

Chavous, T., Bernat, D., Schmeelke-Cone, K., Caldwell, C., KohnWood, L., \& Zimmerman, M. (2003). Racial identity and academic attainment among African American adolescents. Child Development, 74, 1076-1091.

Coard, S. I., Breland, A. M., \& Raskin, P. (2001). Perceptions of and preferences for skin color, Black racial identity, and self-esteem among African Americans. Journal of Applied Social Psychology, 31, 2256-2274.

Cohen, C., \& Nee, C. (2000). Sex differentials in African American communities. American Behavioral Scientist, 43, 1159-1206.

Cokley, K. (2000). An investigation of academic self-concept and its relationship to academic achievement in African American college students. Journal of Black Psychology, 26, 148-164.

Cokley, K. (2001). Gender differences among African American students in the impact of racial identity on academic psychosocial development. Journal of College Student Development, $42,480-487$.

Coleman, J. S. (1990). Equality and achievement in education. Boulder, CO: Westview.

Coleman, J. S., \& Hoffer, T. (1987). Public and private schools. New York: Basic Books.

Crocker, J., \& Major, B. (1989). Social stigma and self-esteem: The self-protective properties of stigma. Psychological Review, 96, 608-630.

Cross, T., \& Slater, R. B. (2000). The alarming decline in the academic performance of African-American men. Journal of Blacks in Higher Education, 27, 82-87.

Davis, J. E. (1995). College in Black and White: Campus environment and academic achievement of African American males. Journal of Negro Education, 63, 620-633.

Eccles, J. S. (1994). Understanding women's educational and occupational choices. Psychology of Women Quarterly, 18, 585-609.

Fleming, J. (1984). Blacks in college: A comparative study of students' success in Black and White institutions. San Francisco: Jossey-Bass.

Flowers, L., \& Pascarella, E. (1999a). Cognitive effects of college racial composition on African American students after 3 years of college. Journal of College Student Development, 40, 669-677.

Flowers, L., \& Pascarella, E. (1999b). The effects of college racial composition on African American college students' orientations toward learning for self-understanding. Professional Educator, 22(1), 33-47.

Fordham, S. (1988). Racelessness as a factor in Black students' school success: Pragmatic strategy or pyrrhic victory? Harvard Educational Review, 58(1), 54-84.

Fordham, S., \& Ogbu, J. (1986). Black students' school success: Coping with the "burden of acting White." Urban Review, 18, 176-206.

Foster, L. (2001). The not-so-invisible professors: White faculty at the black college. Urban Education, 36, 611-629.

Gose, B., \& Hebel, S. (2001, May 18). Judge questions agreement in Mississippi's desegregation case. Chronicle of Higher Education, XLVII(36), A27.

Hall, R. (2001). The ball curve: Calculated racism and the stereotype of African American men. Journal of Black Studies, 32, 104-119.

Hare, N., \& Hare, J. (1991, March/April). African American males on campus: An endangered species. Black Collegian, pp. $126-129$.

Harter, S. (1982). The Perceived Competence Scale for children. Child Development, 53, 87-97.
Hurtado, S. (1992). The campus racial climate: Contexts of conflict. Journal of Higher Education, 63, 539-569.

Hurtado, S., \& Carter, D. F. (1997). Effects of college transition and perceptions of the campus racial climate on Latino college students' sense of belonging. Sociology of Education, 70, 324-345.

Kanter, R. M. (1977). Some effects of proportions on group life: Skewed sex ratios and responses to token women. American Journal of Sociology, 82, 965-990.

Kim, S., \& Sedlacek, W. (1996). Gender differences among incoming African-American freshmen on academic and social expectations. Journal of the Freshman Year Experience and Students in Transition, 8, 25-37.

Lederman, J. (1992, June 17). Blacks makeup large proportion of scholarship athletes, yet their overall enrollment lags at Division I colleges. Chronicle of Higher Education, 38(41), A1.

Lips, H. M. (1992). Gender- and science-related attitudes as predictors of college students' academic choices. Journal of Vocational Behavior, 40, 62-81.

McJamerson, E. M. (1991). The declining participation of AfricanAmerican men in higher education: Causes and consequences. Sociological Spectrum, 2, 45-65.

McJamerson, E. M. (1992). Undergraduate academic major and minority student persistence: Individual choices, national consequences. Equity and Excellence, 25(2-4), 35-48.

Mickelson, R. (1990). The attitude-achievement paradox among Black adolescents. Sociology of Education, 63, 44-61.

Mills, J. R., \& Buckley, C. W. (1992). Accommodating the minority teacher candidate: NonBlack students in predominantly Black colleges. In M. Dilworth (Ed.), Diversity in teacher education (pp. 134-159). San Francisco: Jossey-Bass.

Murguia, E., Padilla, R. V., \& Pavel, M. (1991). Ethnicity and the concept of social integration in Tinto's model of institutional departure. Journal of College Student Development, 32, 433-439.

Nettles, M. T. (1988). Black and White students' academic performance in majority White and Majority Black college settings. In J. B. Williams, III (Ed.), Desegregating America's colleges and universities (pp. 159-178). New York: Teachers College Press.

News and Views. (1998, Summer). White professors teaching at historically Black colleges. Journal of Blacks in Higher Education, 20(3), 62.

Nora, A., \& Cabrera, A. F. (1996). The role of perceptions of prejudice and discrimination on the adjustment of minority students to college. Journal of Higher Education, 67, 119-148.

Osbourne, J. W. (1997). Race and academic disidentification. Journal of Educational Psychology, 89, 728-735.

Pascarella, E., Smart, J., \& Stoecker (1989). College race and the early status attainment of Black students. Journal of Higher Education, 60, 82-107.

Phelps, R. E., Tranakos-Howe, S., \& Dagley, J. C. (2001). Encouragement and ethnicity in African American college students. Journal of Counseling and Development, 79, 90-97.

Robertson, J. M. (2001). Counseling men in college settings. In G. R. Brooks (Ed.), The new handbook of psychotherapy and counseling with men: A comprehensive guide to settings, problems, and treatment approaches (Vol. 1, pp. 146-169). San Francisco: Jossey-Bass.

Sandler, B. R., Silverberg, L. A., \& Hall, R. M. (1996). The chilly classroom climate: A guide to improve the education of women. Washington, DC: National Association for Women in Education.

Sellers, R. M., Chavous, T. M., \& Cooke, D. Y. (1998). Racial ideology and racial centrality as predictors of African American college students' academic performance. Journal of Black Psychology, 24, 8-27.

Simpson, J. (2001). Segregated by subject: Racial differences in the factors influencing academic major between European Americans, Asian Americans, and African, Hispanic, 
and Native Americans. Journal of Higher Education, 72, 63-100.

Smith, T., \& Brody, G. H. (2000). Intra- and extracultural perceptions of competence in rural African American youth. Journal of School Psychology, 38, 407-422.

Steele, C. M. (1992). Race and the schooling of Black Americans. The Atlantic Monthly, 269(4), 68-78.

Steele, C. M. (1997). A threat in the air: How stereotypes shape intellectual identity and performance. American Psychologist, 52, 613-629.

Steele, C. M. (1998). Stereotyping and its threat are real. American Psychologist, 53, 680-681.

Steele, C., \& Aronson, J. (1995). Stereotype threat and the intellectual test performance of African Americans. Journal of Personality and Social Psychology, 69, 797811.
Stumpf, H., \& Stanley, J. (1996). Gender related differences on the College Board's Advanced Placement and Achievement tests, 1982-1992. Journal of Educational Psychology, 88, 353-364.

U.S. Department of Education, National Center for Education Statistics. (1996). Historically Black colleges and universities, 1976-1996 (NCES 96-902).

Wenglinsky, H. H. (1995). The educational justification of historically Black colleges and universities: A policy response to the U.S. Supreme Court. Educational Evaluation and Policy Analysis, 18, 91-103.

Wiley, M. G., \& Crittenden, K. S. (1992). By your attributions you shall be known: Consequences of attributional accounts for professional and gender identities. Sex Roles, 27, 259-276.

Yancey, G. (1994). An examination of the propensity of women and racial minorities to specialize in sex/gender and racial/ethnic relation studies. American Sociologist, 25, 72-76. 